https://artnodes.uoc.edu

\title{
El trauma de lo inerte. Apuntes para una nueva parasitología
}

\author{
Ivan Flores Arancibia \\ Académico. Director Instituto de Artes Visuales, Universidad Austral de Chile
}

Begonya Saez Tajafuerce

Profesora agregada de la Universitat Autònoma de Barcelona

Fecha de presentación: septiembre de 2020

Fecha de aceptación: noviembre de 2020

Fecha de publicación: enero de 2021

\section{Cita recomendada}

Flores Arancibia, Ivan; Saez Tajafuerce, Begonya. 2021. «El trauma de lo inerte. Apuntes para una nueva parasitología». En: Benítez, Laura; Berger, Erich (coord.). «Artes en tiempos de pandemia». Artnodes, núm. 27: 1-9. UOC. [Consulta: dd/mm/aa]. http://doi.org/10.7238/a.v0i27.374375 \footnotetext{
@ $C$ Los textos publicados en esta revista están sujetos -si no se indica lo contrario- a una licencia de
SOCMERIGHISRESERVED
Reconocimiento 4.0 Internacional de CreativeCommons. La licencia completa se puede consultar en
https://creativecommons.org/licenses/by/4.0/deed.es_ES.
}

\section{Resumen}

En el contexto de una crisis ecológica que amenaza el destino de las especies que pueblan la Tierra, incluida la humana, la pandemia causada por el virus SARS-CoV-2 cae en un mundo en extinción. Esto nos obliga a revisar el discurso parasitológico contemporáneo que no ha dejado de articular la lógica del intruso basándose en una concepción afirmativa o incluso bondadosa del parásito. Sean cuales sean los modos de infección parasitaria, una inconfesada dialéctica evolutiva conserva el futuro de lo viviente. Pero si planteamos como originaria la intrusión del parásito y la economía parasitaria como estructural poniendo el énfasis en su negatividad constitutiva, su apertura al futuro debe ser considerada como destitución de todo porvenir. En este planteamiento, lo inerte viene a dar cuenta de dicha negatividad constitutiva en calidad de resto latente que procede como materialización de la contingencia, afectando irreversiblemente al tiempo y a su vivencia, y constituye, de ese modo, un trauma para el mundo y para la vida; el trauma de lo humano que muta para extinguirse. 


\title{
artnodes
}

https://artnodes.uoc.edu

El trauma de lo inerte. Apuntes para una nueva parasitología

\section{Palabras clave}

parásito, extinción, trauma, inerte, tiempo.

\section{The trauma of the inert. Notes for a new parasitology}

\begin{abstract}
In the context of an ecological crisis which threatens the destiny of the species that populate Earth, including the human species, the pandemic caused by the virus SARS-CoV-2 has come to a world hit by extinction. This obliges us to revise the contemporary discourse on parasitology, which has continued to articulate the logic of the intruder by being based on a conception of the parasite that is positive or even benevolent. Whatever the modes of parasitic infection are, an unspoken evolutionary reasoning is protecting the future of that which is living. But if we understand the intrusion of the parasite as inceptive and the parasite economy as structural, placing the emphasis on their constitutive negativity, their opening into the future must be considered as a dismissal of all that is to come. In this approach, that which is inert begins to account for said constitutive negativity in the role of a latent remainder that proceeds as a materialisation of possibility, irreversibly affecting time and its experience, and in this way constitutes a trauma for the world and for life; the trauma of that which is human, that which is mutating in order to extinguish itself.
\end{abstract}

\section{Keywords}

parasite, extinction, trauma, inert, time

\section{Introducción}

«même si dans l'avenir l'humanité contrôle le Sida, le traumatisme a irréversiblement affecté, jusque dans ses zones symboliques les plus inconscientes, l'expérience du désir et de ce qu'on appelle tranquillement l'intersubjectivité.» (Derrida, 1989)

Por más inédita que nos parezca la actual Imagenn del mundo, lo que estamos experimentando se ha venido desarrollando desde hace tiempo en cámara lenta. No es que el parásito hubiera infectado un día al mundo, como si el mundo se hubiera dejado habitar, de pronto, por un intruso. El parásito no tiene edad (Derrida, 1989). Sin embargo, su impacto en los discursos se puede datar históricamente. Particularmente desde 1980 , contemporáneo de la Revolución Cibernética y del éxtasis de la información, del avance del neoliberalismo y del virus VIH/SIDA, la lógica parasitaria se transformó en lógica cultural (Bardini, 2006). El parásito infectó el horizonte de las investigaciones más diversas y de los discursos más heterogéneos: la dinámica de la inmanencia (Deleuze y Guattari, 1980) y de la relación (Serres, 1980), de los cuerpos (Haraway, 1985) y de los medios (Rushkoff, 1994), de las interfaces informáticas (Hayles, 1999) y de las redes (Shaviro, 2003), de lo digital (Parikka, 2015) y de los nuevos materialismos (Braidotti, 2002). «Todo lo que en la modernidad era signo en la posmodernidad se convirtió en hipervirus» (Land, 2012).

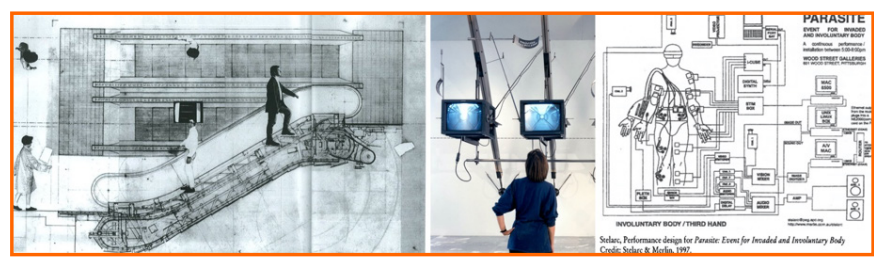

Imagen 1. Izquierda: Elizabeth Diller/Ricardo Scofidio. Para-site (1989). Derecha: Stelios Arcadiou Parasite (1997).

Jacques Derrida propuso el término teleretórica (télérhétorique) para describir el espacio discursivo de esta transformación cultural que despojó al virus y al parásito de sus determinaciones biológicas (Derrida, 1989). No se trataba de un simple traslado metafórico. En un contexto donde la economía política del poder y la imaginación, las relaciones humanas y la propagación de acontecimientos operan en niveles cada vez más abstractos, en el nivel de los códigos de programa (Flusser, 2011) y de la dataesfera, en niveles neuronales 0 en interacciones moleculares del cuerpo, el parásito y lo viral comenzaron a describir la infraestructura misma de lo real. Ahora bien, dentro de lo que podemos denominar la primera convergencia viral iniciada en 1980, la lógica parasitaria de las transducciones 0 evoluciones aparalelas, las dinámicas entre lo no vivo y lo vivo, lo artificial y lo orgánico, los códigos y lo molecular, contiene una dialéctica evolutiva sobre la interacción entre cuerpos y medios. La evolución es parasitaria. 0, como decía Serres, «el parásito le da al huésped los medios para estar a salvo del parásito» (Serres, 1980). 


\section{artnodes}

https://artnodes.uoc.edu

El trauma de lo inerte. Apuntes para una nueva parasitología

En otros términos, el parásito ofrece los medios para conservar el futuro de lo viviente. Conserva la forma temporal del futuro' 1 . Operador de una metamorfosis incesante, «el virus - dice Emanuele Coccia en un libro que resume la parasitología contemporánea- es el modo en que el futuro existe en el presente», esto es, el modo en que una especie muta desde el punto de vista de la evolución (Coccia, 20202).

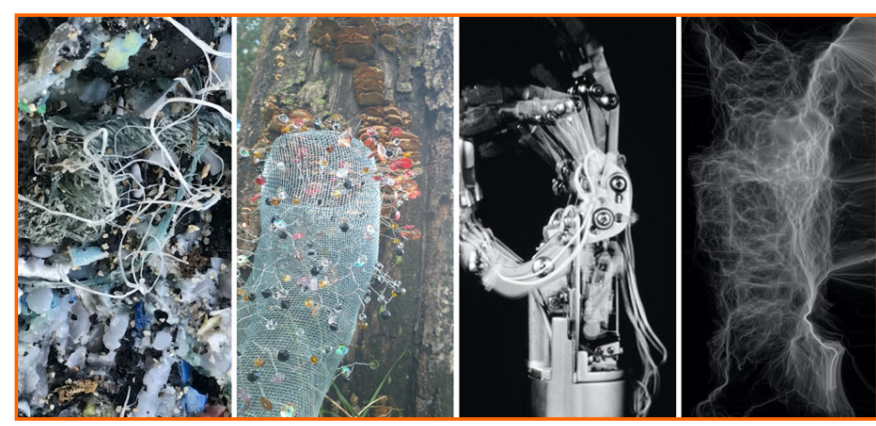

Imagen 2. De Izquierda a derecha: Benjamin Weinger. Plastics Research (2018); Jesús Román Paisaje anorgánico (2019); Stelios Arcadiou. Third Hand (1980); E. Fischer. Tweetnetworks Map (2014).

Luego de esta primera convergencia viral, el hipervirus retorna. Pero los datos son distintos. En el contexto de una crisis ecológica que amenaza el destino de las especies que pueblan la Tierra, incluida la especie humana, la pandemia causada por el virus SARS-CoV-2 cae en un mundo en extinción. Un mundo donde la forma temporal del futuro está en cuestión. Esto nos obliga a revisar el discurso parasitológico contemporáneo. Si aceptamos la intrusión originaria del parásito, escribía Derrida, no solo aceptamos su apertura al futuro, sino el rastro mortal de un tercero como algo que no se abre al futuro. Un tercero que no trabaja en el mantenimiento de su medio (Colebrook, 2014). Mientras no consideremos esta negatividad del parásito, no abordaremos el futuro de la extinción.

Dentro de lo que Derrida denominó parasitología o virología general, el propósito de este texto es prestar atención a la figura del parásito como tercero inerte. Fuera de los elementos de una relación, fuera de los cuerpos, el parásito no puede ser. Con todo, la hipótesis de la cual partimos es que lo inerte opera como trauma de lo humano, entendiendo por trauma, en la estela freudiana, una instancia afectiva vinculada a un hecho sucedido en el pasado, cuyo recuerdo se ve reactivado de acuerdo a una lógica contingente y cuya representación intolerable retorna tras haber sido reprimida no sin que ello comporte un goce subjetivo que toca al cuerpo y que da cuenta de la ontología de un inexistente que, paradójicamente, $e s^{3}$. Sería justamente la extinción del parásito fuera de los elementos de una relación, es decir, su condición de objeto inerte, lo que compone una temporalidad de la extinción que traumatiza la historia. Es esta agencia del parásito cuando aparentemente no está en relación con los cuerpos, cuando opera sin un medio de reproducción, lo que nos inquieta. En este sentido, nos preguntamos aquí acerca de la declinación temporal, de la forma agentiva y de la estructura mutacional del trauma de lo inerte, con el propósito de abordar la lógica parasitaria en un mundo en extinción.

\section{El tiempo como/de la extinción}

Mientras nos informamos del avance de la pandemia causada por el virus SARS-CoV-2, un informe científico indica que nunca la humanidad había producido más basura electrónica (Global E-waste Monitor, 2020). A medida que el mundo se actualiza a la tecnología inalámbrica 5G, una actualización que el parásito SARS-CoV-2 está efectivamente mediando, se producirá un aumento exponencial de los desechos electrónicos debido a la obsolescencia de millones de dispositivos. Objetos inertes y no muertos, desechos y fósiles técnicos, lo «no muerto de una historia de los medios» (Parikka, 2015), que es también una historia de la contaminación generaliza del mundo. De la roca plastiglomerada a la atmósfera inalámbrica, nuestro mundo es una tecnoesfera parasitaria inerte. ¿Qué temporalidad tiene este desierto de fósiles inertes en el que habitamos?

Si la lógica de lo viviente, que es ella misma una tecnología parasitaria, surge en oposición o ruptura respecto de la materia inerte, surge por una especie de animatogénesis, lo que inquieta es precisamente esta inanimatogénesis (Wills, 2016) como producción exponencial de lo inerte. La ecotecnia (Nancy, 2003) no es solo la producción de cuerpos hiperconectados en

1. Desde una perspectiva deleuziana y posthumanista, aquí discutida, la estructura parasitaria de la vida responde a una coevolución. Si bien este término no sigue el sentido darwiniano de desarrollo simbiótico de especies que comparten el mismo medio, sino el sentido de una simbiosis ecotécnica entre lo vivo y lo no vivo, permanece incuestionado «un ímpetu temporal o evolutivo de la variación» como unidad de la vida. Permanece incuestionado el post de lo humano. "Es porque la vida es parásita de la materia» que existe una trayectoria irreversible del tiempo de la vida que produce «más diferenciaciones tanto dentro de la vida como dentro de la materia, así como entre ellos. Darwin ha producido, de hecho, una nueva ontología, una ontología de las implacables operaciones de la diferencia» (Grosz, 2011). Como se verá hacia el final de este articulo, esta eficacia temporal de la inmanencia de la vida contrasta con la eficacia temporal de la extinción.

2. La homologación entre virus y futuro en el libro de Coccia, el futuro como enfermedad de todas las especies, retoma el «significado más profundo de la teoría de la evolución de Darwin», a saber, «toda vida es la gestación continua de una metamorfosis, cuyo resultado solo es visible en el futuro» (Coccia, 2020).

3. En la primera elaboración del trauma que Freud lleva a cabo junto a Breuer en Estudios sobre la histeria (1893-1895), como «trauma psíquico», este remite a la imposibilidad de tramitar un afecto generado por una impresión inasumible mediante los mecanismos de la consciencia, la cual tiende, entonces, a olvidarse, dando lugar a una huella en la memoria o recuerdo inconsciente (cfr. Freud, 1894). Lo interesante en este contexto es que «no son las vivencias mismas las que poseen efecto traumático, sino solo su reanimación como recuerdo» (Freud 1896a:162). 


\section{artnodes}

https://artnodes.uoc.edu

El trauma de lo inerte. Apuntes para una nueva parasitología

interfaces. Es también producción de lo inerte, «materia inerte organizada», que no solo se transforma en el tiempo como la materia viva en interacción con el medio (Stiegler, 2002), sino que organiza lo inerte como tiempo en extinción.

Precisamente, la primera coordenada en la que se hace valer lo inerte como trauma de lo humano es el tiempo. El trauma se hace manifiesto tanto en la consideración del tiempo como tal, es decir, como instancia ontológica, y, en particular, como tiempo infinito y diferenciado y, por tanto, articulado en la secuencia pasado-presente-futuro, cuanto en la vivencia humana de ese tiempo, que en un totalitario gesto antropocéntrico presupone ya siempre el tiempo como humano y, de ahí, lo humano como devenir y, a la vez, como porvenir.

Lo inerte viene a desmentir sendos presupuestos en la medida en que cancela el carácter infinito y diferenciado del tiempo -de lo humano- inoculando en él y en su vivencia un valor de contingencia radical. Ese valor se hace operativo mediante la paradoja que constituye a lo inerte entre la vida y la muerte, y según lo cual existe a la vez en el tiempo y fuera de él. El tiempo propio de lo inerte, que viene a intervenir afectivamente lo humano y su vivencia del tiempo y, de esa forma, a sacarlo del quicio en que el tiempo significa todo lo que es, es la latencia. Eso que lo inerte inocula en el tiempo -así como en la historia- es el lapso y, en concreto, el lapso sin medida entre la causa y el efecto. El lapso pasa a ser la medida del tiempo para la cual no hay medida, pues el lapso es justamente cifra de la contingencia que viene a traumatizar la lógica causal que es la que obra en el tiempo de sus éxtasis: pasado-presente-futuro.

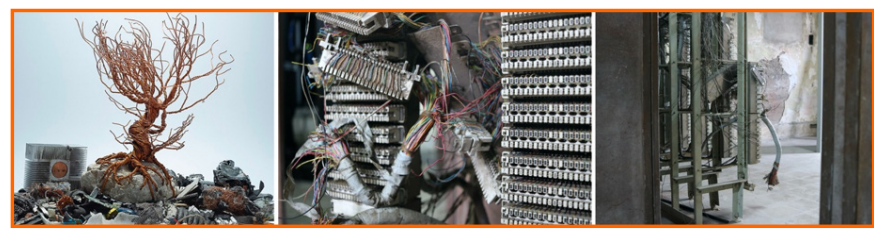

Imagen 3. Izquierda: Global E-waste Monitor (2020). Centro y derecha: Ivan Flores Arancibia Archaeology of Mutation. Ars Electronica (2020).

Sin los medios para llevar a cabo sus planes, sin el aparato necesario para copiar o traducir, escribía François Jacob, «el virus no es más que un objeto inerte, como una cinta fuera de la grabadora» (Jacob, 1970). Nadie, ninguna ciencia o discurso, discute esto: que el virus contagia cuando entra en relación con otro cuerpo. La gestión política y sanitaria de la actual pandemia consiste en confinar los cuerpos para extinguir el medio de propagación del virus. El parásito no ataca, en realidad, los cuerpos, sino sus relaciones. Ataca sus mediaciones (Serres, 1980). Cuando el parásito no entra en las relaciones, existe en el modo de la inexistencia; insiste en estado latente. En ese modo de infravida-se nos sugiere en una avalancha de estudios epidemiológicos- no dura nada. Dura sin porvenir, des- aparece en el aire 0 en las superficies en un tiempo que podemos calcular mientras nos lavamos las manos o esquivamos la respiración de los otros. Sin embargo, la latencia de lo inerte tiene un tiempo incalculable.

El recurso metafórico de la reflexión de Jacob -que bien sabemos hoy que no es una simple metáfora- que entrecruza el parásito como objeto biológico inerte y el parásito como objeto tecnológico inerte, introduce un dilema temporal porque el objeto técnico inerte -el que guardamos en algún cajón del hogar o el que arrojamos a la basurabajo ningún aspecto deja de agenciar el tiempo. Como argumenta Wolfgang Ernst, los objetos tecnológicos inertes «no están muertos, permanecen en latencia: para convertirse en medios, necesitan ser cargados con electricidad y ser puestos en operación. Desde la perspectiva de la cinta magnética, la reproducción grabada es tan auténtica hoy como lo podría haber sido cincuenta años atrás (lo que prueba que el tiempo tecnológico permanece autónomo) -un intervalo de tiempo, no una distancia histórica-» (Ernst, 2016: 110). Lo inerte permanece en el modo de un tiempo diferido, «en un estado liminal de latencia -literalmente en un entre (in-between) medial-» (Ernst, 2016: 111). En otros términos, lo inerte no desaparece degradado a la categoría de lo «no contagioso» o de lo que está «obsoleto», sino que abre una espontaneidad temporal otra que sigue operando más allá de las divisiones que protegen la vida. Esta autonomía temporal de lo inerte traumatiza el tiempo de lo humano -y de la historia- al introducir la paradoja de un lapso temporal que es la medida de la extinción de lo humano.

Desde el punto de vista de la representación humana, la sensación del tiempo es inseparable de la medida entre $(\mu \in \tau \alpha \xi v \tau \iota$ ov $\tau 0 \nu$ $\eta \tau \epsilon \rho 0 \nu)$ un antes y un después (Aristóteles, 1995: 219 a 25-26). La sensación del tiempo requiere de un intervalo $(\delta\llcorner\alpha \sigma \tau \eta \in \mu \alpha)$ de auto-afección, especie de rhema ( $(\eta \mu \alpha)$ puro por el que el sujeto pronuncia en el alma el paso del tiempo. Pero no acontece lo mismo respecto de la latencia temporal de lo inerte -el parásito biológico 0 tecnológico-que abre un intervalo, un lapso, que pasa a ser la medida de un tiempo para el cual no hay medida, no hay una secuencialidad, sino un diferimiento que viene a traumatizar la lógica causal que es la que el parásito obra en el tiempo como contingencia radical. Dicho de otro modo: por ser ese entre la vida y la muerte, por ser latencia, lo inerte traumatiza el tiempo -de lo humano-y su vivencia; afecta su forma de ser, infinita y diferenciada, transformándola. Dicha transformación consiste en despojar a lo humano de porvenir. Es decir, lo inerte afecta al mundo porque afecta al tiempo del mundo que deviene, en esa afección, otro de sí mismo. La afección de lo inerte opera, por tanto, como hetero-afección en la medida en que hace valer una temporalidad parasitaria en el mundo que desquicia el tiempo del mundo. El tiempo -de lo humano-y su vivencia conservan la forma de devenir, que, sin embargo, pierde su esencia infinita y diferenciada. Es así que el tiempo viene a ser determinado como/ de la extinción. 


\section{artnodes}

https://artnodes.uoc.edu

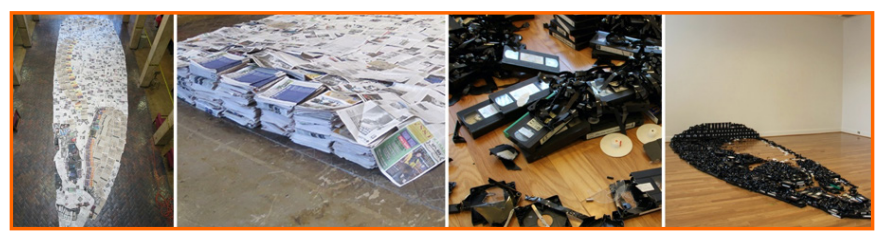

Imagen 4. Noah Scalin. Dead Media. 2012-2016. Proyecto anamórfico con distintos objetos técnicos obsoletos.

Inerte como una cinta fuera de la grabadora, el parásito que inquieta es el que contagia sin relación, el que permanece en estado de latencia e infecta sin futuro. La declinación temporal de lo inerte saca de quicio al tiempo del mundo. Ocurre aquello que no puede ocurrir y persiste aquello que no puede persistir. El tiempo de lo inerte, el tiempo del parásito, no se ordena en la escala de lo dejado atrás y de lo nuevo; se diagrama, más bien, en el orden heterocrónico de un trauma del tiempo del mundo. Esa es la vivencia del tiempo a la que lo inerte aboca lo humano. Se trata de la vivencia de una imposibilidad estructural, de un fallo en el sistema, de una tara en el tejido. Lo inerte hace valer una temporalidad no humana que afecta el tiempo de la continuidad orgánica del mundo y de la vida. Lo inerte no procura su pervivencia. La forma agentiva de lo inerte -ya sea el virus o el aparato técnico- no responde a la lógica causal que sostiene todo porvenir. El trauma de lo inerte resulta altamente inquietante, porque nos sume en una temporalidad estática. Nos sume en la extinción que dice el tiempo, que es un tiempo heteroafectivo, de lo inerte.

\section{La agencia del parásito}

Lo que empezó a contar bajo nuestros pies, como en un cuadro de Pollock, era el plan de consistencia (Deleuze y Guattari, 1980). Un campo intrascendente, es decir, sin trascendencia, definido por la contaminación de lo viviente y la polución de los códigos. No se trataba de ninguna metáfora. Era «la abolición de toda metáfora: todo Io que consiste es Real» (Deleuze y Guattari, 1980). Lo que cuenta en un plan de consistencia son las relaciones. No los elementos, sino el entre. Ni vivo ni muerto, el parásito, precisamente porque circula entre, constituyó la forma operativa de este campo intrascendente. No la forma de vida como la conocíamos, porque la vida en este plan de consistencia no sería más que una máquina abstracta que parasita los flujos. En lugar de estar arrojados en el mundo, envueltos en signos y en lenguajes, el modelo que determina este paisaje intrascendente es el de la contaminación vírica (Shaviro, 2003; Braidotti, 2002). El parásito designó el esquema de un desplazamiento epistémico: el paso de una subjetividad prostética a una subjetividad inervada donde es imposible distinguir los cuerpos de sus extensiones tecnológicas (Haraway, 1988). Si los desplazamientos epistémicos tienen aspecto estético, como sugería Foucault en su análisis de Las Meninas, nuestra época se resumiría en Suspension(1997) de Jordan Crandall o Visions of Japan de lko Toyo. En el supuesto de que uno pudiera pararse frente a esta instalación, sentirá que el aparato proyectivo de la modernidad ha mutado en un aparato de inmersión en cuyo centro, en un campo de flujos electromagnéticos, intensidades numéricas y aceleración de datos, «al mínimo, quebradizo cuerpo humano», como decía Walter Benjamin, solo le queda la posibilidad de sincronizarse y contagiarse en el medio como encarnación procesual de la información. Siguiendo a Deleuze, este plano de consistencia no tiene nada de negativo. Es pura afirmación de la coevolución parasitaria entre un cuerpo, tomado en su dimensión material, y su medio.

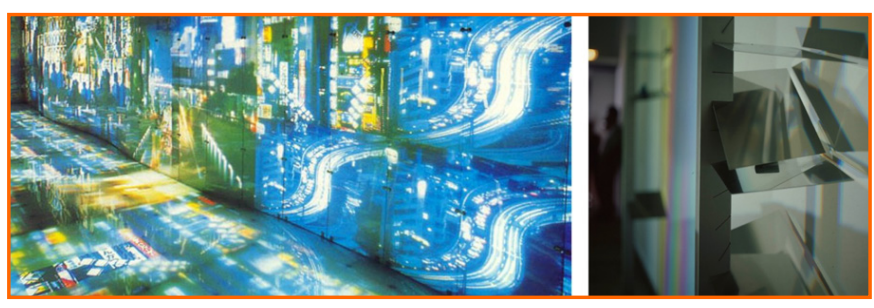

Imagen 5. Izquierda: Toyo Ito. Visions of Japan (1991). Derecha: Jordan Crandall. Suspension (1997).

Mientras que, en el plano de consistencia, el agenciamiento del parásito moviliza la disolución de la diferencia entre lo vivo y lo no vivo - «no existe base para oponer ontológicamente lo orgánico, lo técnico y lo textual» (Haraway, 1988)-, remarcando no solo la inervación de la tecnología, sino la emergencia de un nuevo cuerpo, una sobrevida de lo humano, nuestra preocupación traza un camino inverso: si la vida humana es originariamente parasitaria, entonces, ¿qué formas adquiere dentro de esta «vida» lo inerte y la latencia del parásito? Nos interesan menos los nuevos cuerpos posthumanos que el hecho de que cualquier cuerpo vivo supone un encuentro con lo inerte y latente. A diferencia de los objetos que constituyen nuestro sistema técnico construido, cuyo estatuto tecnoparasitario no está en duda desde hace años, el parásito técnico inerte parece haber sido omitido. Y, junto con esta omisión, la negatividad irreductible del plan de consistencia maquínico.

Si somos seres autopoéticos, encarnados, sintonizados, receptivos, dinámicos y dependientes de este sistema informático, se preguntaba hace algunos años Claire Colebrook, «¿cómo es que hemos actuado de tal manera que hemos creado un futuro que ya no será un medio para los organismos que somos? Si los humanos están tan unidos a un mundo que es en sí mismo un todo vivo que se mantiene a sí mismo, ¿cómo se afianzó la destrucción de este dominio simbiótico de la vida?» (Colebrook, 2014: 137). Aunque en estas preguntas no hay necesariamente una crítica al devenir molecular, codificado y animal de nuestros cuerpos, sí llama la atención sobre la trayectoria autodestructiva inmanente del parásito. Que no podamos concebir el mundo o la vida sin dar cuenta de cómo actúa en 


\section{artnodes}

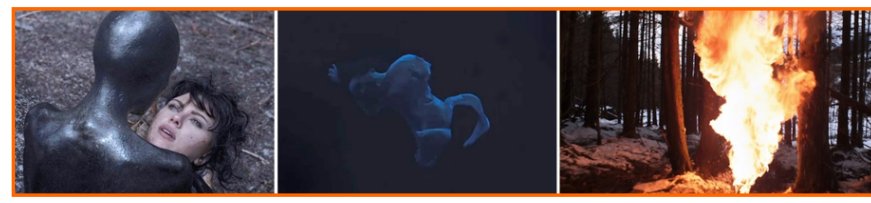

Imagen 6. Jonathan Glazer. Under the Skin (2013).

ellos lo parasitario, implica necesariamente, a nuestro juicio, abordar esta trayectoria negativa del parásito, porque, de acuerdo a ella, su condición de agente de relaciones mutantes queda de alguna manera suspendida. 0 diferida. Como sucede con la impresión traumática y su huella. A contrapelo de los discursos afirmativos de la contaminación viral, Derrida -a quien no se podría acusar de no haber construido una filosofía sobre el suplemento como parásito y la contaminación como génesis- escribía que el parásito, que no está ni vivo ni muerto, introduce en el seno «de la intersubjetividad la huella mortal e indestructible del tercero. No del tercero como condición de lo simbólico y de la ley, sino del tercero como estructuración desestructuradora del vínculo social» (Derrida, 1992: 264). Un tercero, diríamos, de la no-relación, un tercero inerte que, más allá de cualquier normalidad, traumatiza todas las relaciones y los tiempos.

Así pues, ¿en qué sentido y en qué medida cabe atribuir agencia al parásito? Nos preguntamos por el carácter contra-performativo de lo inerte, es decir, por los términos en que lo inerte debe ser considerado principio activo del mundo, de la realidad, sin perder de vista que se trata de una instancia afectiva y que, por tanto, la acción de lo inerte viene marcada por la paradoja. Hemos dicho que lo inerte inocula la contingencia en la lógica causal, enajenándola, y es así como literalmente interviene en el mundo y en la vida de lo humano. La agencia-y, con ella, la economía- parasitaria carece de porvenir, en la medida en que la acción de lo inerte, como hemos dicho, no se abre al futuro, sino que queda retenida en el diferimiento absoluto que obra. La latencia es precisamente cifra de esa temporalidad propia de lo inerte que deviene, entonces, afección. No solo comporta lo inerte el trauma de la acción en el sentido en que esta no puede ser ya comprendida en una temporalidad al uso, sino también porque la acción de lo inerte no se inserta de forma unívoca ni exclusiva en una lógica causal y, por tanto, no acontece en la historia como la conocemos ni obedece a los mecanismos que dicha lógica presupone, como la previsión o la anticipación. Pero, además, dada su condición fundamentalmente latente, la agencia del parásito tiene un carácter pasivo, lo cual explica y se hace evidente a la vez en el hecho de que no requiera de contacto para que su «reanimación» y, así, el contagio mismo se hagan efectivos.

Es preciso preguntarse por la agencia material, es decir, por la agencia de la materia en la medida en que el parásito no obra en calidad de sujeto. Karen Barad (2003) afirma que un análisis posthumano de la performatividad -y, por tanto, de la agentividadno da cuenta solo de «la formación del sujeto», sino también de «la producción de la materia», así como de su historicidad, en tanto que materia corpórea (Barad, 2003: 808). La materia

«is not an individually articulated or static entity. Matter is not little bits of nature, or a blank slate, surface, or site passively awaiting signification; nor is it an uncontested ground for scientific, feminist, or Marxist theories. Matter is not a support, location, referent, or source of sustainability for discourse» (Barad 2003: 821).

La primera cuestión que plantea Barad y que resulta relevante en este contexto es que la agencia material excede el orden discursivo y, por tanto, representacional. Eso significa que la acción que lleva a cabo la materia y que dice la forma agentiva de lo inerte excede también la historia en tanto narrativa histórica. La única forma de narración posible en este contexto traumático que protagoniza el parásito y su acción es de orden material. Dice Barad al respecto que el mundo «is an ongoing open process of mattering through which 'mattering' itself acquires meaning and form in the realization of different agential possibilities» (Barad 2003: 817-818). Esto implica que, tomado en la dimensión material de lo inerte, lo que el parásito obra es una "ongoing performance of the world in its differential intelligibility» (Barad, 2003: 821). Eso es lo que cabe entender por mattering.

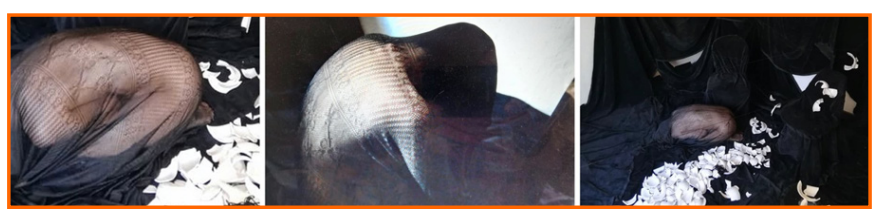

Imagen 7. Ana Barros. Latencia (2020).

Lo relevante es que toda acción de la materia comporta una intervención en el mundo que altera su orden también discursivo en la medida en que afecta a su inteligibilidad. Sin embargo, lo que observamos en la acción del parásito es que esa afección es irreversible. La coordenada de la acción da cuenta de otro ámbito de enajenación por acción del parásito, a saber, de la enajenación de la inteligibilidad del mundo y de la vida. Estos son intervenidos materialmente por lo inerte y en esa intervención se hace valer de manera radical la negatividad.

\section{La mutación de la mutación}

Por supuesto, seguimos hablando del tiempo histórico. Seguimos preguntándonos, como lo muestra la reciente versión del festival Ars Electrónica 2020, cómo será el mundo después de la actual pandemia. Pero ya no vivimos en el tiempo histórico. Al menos, no vivimos en el tiempo según la representación humana del antes y del después. Entre el pasado incautado en mecanismos de reproductibilidad técnica y el futuro amenazador de la extinción, el presente se ha convertido en un 


\section{artnodes}

https://artnodes.uoc.edu

El trauma de lo inerte. Apuntes para una nueva parasitología

lapso dilatado. Estamos en una suerte de desplazamiento intransitivo. Aquí y allá los pueblos están en revueltas insurgentes. La sensación o la afección, sin embargo, es que no habrá una revolución. Que cierto automatismo material del tiempo, una temporalidad estática, parasitaria, introduce en nuestro imaginario sobre la irreversibilidad del tiempo de la vida, la contingencia radical de la irreversibilidad de la extinción. El parásito no es la forma en que el futuro existe en el presente, sino la forma en que el presente dura sin porvenir.

¿No es esta contingencia radical lo que estamos obligados a pensar? No se trata de pesimismo, sino de realismo parasitario. Según Colebrook, una especie solo puede sobrevivir por mutación parasitaria, es decir, no siendo ella misma. Al mismo tiempo, sin embargo, también por mutación parasitaria, cualquier especie -en esa supervivencia- puede afectar su medio hasta la destrucción general. Esto abre, según Colebrook, dos modalidades del trauma: 0 bien la especie se orienta de tal manera que no percibe los efectos que están traumatizando su medio, o bien está imposibilitada de objetar los efectos que están traumatizando el organismo hasta su disolución. Por sobre estas modalidades del trauma, hay, sin embargo, un tercer trauma que envuelve la cuestión del medio y del organismo, a saber, el trauma que la máquina abstracta del capital introduce en el tiempo. Esa máquina, como lo sabemos desde Karl Marx -«El capital es trabajo muerto, que, como un vampiro, se reanima succionando trabajo vivo» (Marx, 2010: 279-280)- a Mark Fisher -«El capital es un parásito abstracto, un vampiro insaciable y creador de zombis» (Fisher, 2009) - parasita todos los niveles de la realidad. No solo hace rizomas mutantes entre especies; hace rizoma con el mundo reformulando el tiempo del mundo como extinción. La pregunta radical concierne entonces al tiempo de la extinción de este parasitismo estructural, tiempo estático sin sobrevivencia. La máquina abstracta del capital es la extinción misma deviniendo.

«La extinción tiene una eficacia trascendental precisamente en la medida en que indica una aniquilación que no es ni una posibilidad hacia la que podría orientarse la existencia actual, ni un dato dado del que podría partir la existencia futura. Inhabilita retroactivamente la proyección, así como anula preventivamente la retención. En este sentido, la extinción se desarrolla en una "posterioridad anterior" que usurpa la "anterioridad futura" de la existencia humana.» (Brassier, 2007)

El parásito le da al huésped los medios para su extinción. En el tiempo como/de la extinción la mutación es sujeto de mutación. No se trata, como afirma Jean-Luc Nancy (Garrido, 2020), de una consciencia «inquieta de sí» que procura un cambio o una transformación que altera el curso lineal de la historia dando lugar a un orden nuevo. Lo inquieto aquí es la mutación misma que muta en su propia extinción. En eso reside la eficacia trascendental de la extinción. La eficacia del parásito como tercero inerte. En un tono similar a lo que se podría encontrar en Under the Skin de Jonathan Glazer, esta eficacia implica considerar no solo el avance de las mutaciones entre cuerpos, sino las mutaciones sin sobrevivencia. En esta perspectiva, el parásito está unido a su medio por una mutación que no se abre al futuro. A esta ausencia de porvenir en la mutación misma es a lo que denominamos el trauma de lo inerte. La mutación lo es de la mutación misma, negatividad radical de lo inerte que pone en obra el parásito.

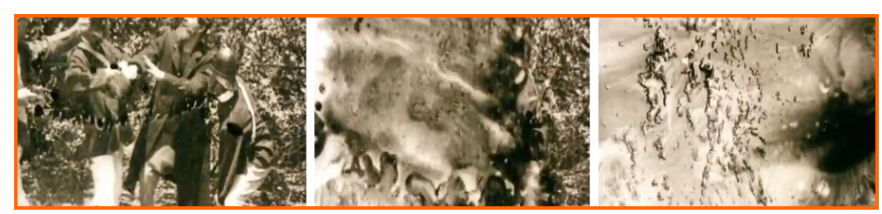

Imagen 8. Charles Tait. The Story of the Kelly Gang (1906).

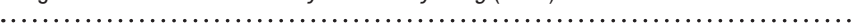

Las imágenes pertenecen a la película The Story of the Kelly Gang de Charles Tait, estrenada el año 1906 en el Athenaeum Hall de Melbourne. Considerado el primer largometraje de la historia, su estreno fue un acontecimiento. Sin embargo, la película se perdió hasta convertirse en un objeto inerte. Obedeciendo a la mera contingencia, unos pocos fragmentos aparecieron en 1978. En 1980, otros metrajes se encontraron en un basurero. En noviembre de 2006, el National Film and Sound Archive de Australia realizó una restauración digital que permitió ver diecisiete minutos de una película que duraba originalmente más de una hora. Pero la restauración digital no eliminó el deterioro del material. Hizo algo más radical: eternizó la extinción que se fue imprimiendo en el medio fílmico. Lo que hoy nos inquieta de esta película no es la magia de la imagen en movimiento que pudo fascinar a sus primeros espectadores. Lo que nos inquieta es el abrasador avance de la extinción alrededor de los cuerpos. La película, en cierto modo, dejó de actualizar la secuencia capturada. En ausencia de público y de autoría, en un tiempo de latencia, comenzó a actualizar la inmanencia de una aniquilación que estaba operando ahí mismo donde había nacido la imagen. Corroídos por un trauma que los disuelve y, de esa forma, los constituye, los cuerpos obran una extinción cuya inmanencia se proyecta como la insistente negatividad de la mutación.

\section{Referencias bibliográficas}

Aristóteles 1995. Física [Trad. Guillermo R. de Echandía]. Madrid: Gredos.

Barad, Karen. 2003. «Posthumanist Performativity: Toward an Understanding of How Matter Comes to Matter, Signs». Journal of Women in Culture and Society, 2003, vol. 28(3). D0l: https://doi. org/10.1086/345321

Bardini, Thierry. 2006. «Hypervirus: A clinical report». CTheory, febrero 2006. www.professores.uff.br/ricardobasbaum/wp-content/ uploads/sites/164/2020/04/Bardini_Hypervirus-A-ClinicalReport-CTheory.pdf. 


\section{artnodes}

https://artnodes.uoc.edu

Braidotti, Rossi. 2002. Metamorfosis. Hacia una teoría materialista del devenir. Madrid: Akal.

Brassier, Ray. 2007. Nihil Unbound Enlightenment and Extinction. New York: Palgrave MacMillan. D0I: https://doi. org/10.1057/9780230590823

Coccia, Emanuele. 2020. Métamorphoses. Paris: Rivages.

Colebrook, Claire. 2014. Death of the PostHuman. Michigan: Open Humanities.

Deleuze, Gilles, y Félix Guattari. 1980. Mille Plateaux. Capitalisme et schizophrénie. Paris: Les Éditions de Minuit.

Derrida, Jacques. 1989. «Rhétorique de la drogue». Autrement, série «Mutations», 106: L'esprit des drogues?, abril.

Derrida, Jacques. 1992. Points du suspension. Paris; Galilée.

Ernst, Wolfgang. 2016. Chronopoetics. The Temporal Being and Operativity of Technological Media. New York: Rowman \& Littlefield.

Fisher, Mark. 2009. Capitalist Realism: Is There No Alternative? Alresford: Zer0 Books.

Garrido, Juan Manuel. 2017. «Phraser la mutation : entretien avec Jean-Luc Nancy». Les Cahiers Philosophiques de Strasbourg [En línea], 42 | 2017, mis en ligne le 03 décembre 2018, consulté le 14 septembre 2020. https://journals.openedition.org/ cps/363\#quotation. D0I: https://doi.org/10.4000/cps.363.

Gorsz, Elizabeth. 2011. Becoming undone. Darwinian reflections on life, politics, and art. Durham; London: Duke University Press. D0I: https://doi.org/10.1215/9780822394433

Haraway, Donna. 1988. «La biopolítica de los cuerpos postmodernos». En Ciencia, cyborgs y mujeres. Catedra: Madrid, 1991.
El trauma de lo inerte. Apuntes para una nueva parasitología

Haraway, Donna. 1985. «Manifiesto para cyborgs: ciencia, tecnología y feminismo socialista a finales del siglo XX». En Ciencia, cyborgs y mujeres. Madrid: Catedra, 1991.

Hayles, Katherine. 1999. How We Became Posthuman. Chicago: University of Chicago Press. DOI: https://doi.org/10.7208/chicago/9780226321394.001.0001

Jacob, François. 1970. La logique du vivant. Paris: Gallimard.

Land, Nick. 2012. Fanged Noumena. Collected Weitings 1987-2007. London: Urbanomic.

Marx, Karl. 2010. El Capital. Crítica de la Economía política. Libro primero, editado por Pedro Scaron. Madrid: Siglo XXI.

Nancy, Jean-Luc. 2003. Corpus. Madrid: Arena Libros.

Parikka, Jussi. 2015. A Geology of Media. London: Minesota Press. D0I: https://doi.org/10.5749/minnesota/9780816695515.001.0001

Parikka, Jussi. 2007. Digital Contagions. A Media Archeology of Computer Viruses. London: Peter Lang

Parikka, Jussi. 2007. «Contagion and Repetition: On the Viral Logic of Network Culture» Ephemera 7(2): 287-308.

Rushkoff, Douglas. 1994. Media virus. Hidden Agendas in Popular Culture. New York: Ballantine Books.

Shaviro, Steven. 2003. Connected, or What It Means to Live in the Network Society. Minneapolis: University of Minnesota Press.

Serres, Michel. 1980. Le parasite. París: Grasset.

Stiegler, Bernard. 2002. La Técnica y el Tiempo I. Hondarribia: Hiru.

Wills, David. 2016. Inanimation. Theories of Inorganic Life. Minneapolis: University of Minnesota Press DOI: https://doi.org/10.5749/ minnesota/9780816698820.001.0001

Global E-waste Monitor: http://ewastemonitor.info/ 


\section{artnodes}

https://artnodes.uoc.edu

El trauma de lo inerte. Apuntes para una nueva parasitología

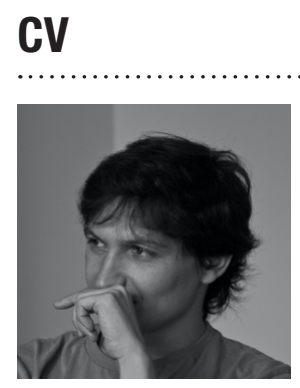

\section{Ivan Flores Arancibia}

Académico. Director Instituto de Artes Visuales,

Universidad Austral de Chile

ivan.flores@uach.cl

Ivan Flores Arancibia. Académico y Director del Instituto de Artes Visuales de la Facultad de Arquitectura y Artes de la Universidad Austral de Chile (UACh). Doctor en Filosofía por la Universidad Autónoma de Barcelona. Ha sido curador y coordinador del proyecto Mutaciones de la UACh en el festival Ars Electronica 2020, investigador de La Escocesa (Barcelona) con el proyecto El entre y el medio (2019-2020), dirige el proyecto FONDART Diferencias tecnológicas y happening extendido en Ronald Kay (2018-2020). Actualmente trabaja en la publicación del libro De la Metaxología. El problema del entre en el pensamiento contemporáneo (Metales Pesados, Chile, 2021).

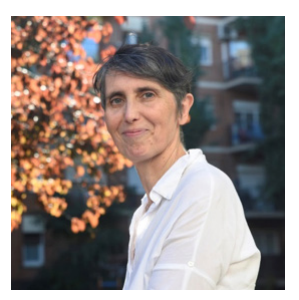

\section{Begonya Saez Tajafuerce}

Profesora agregada de la Universitat Autònoma de Barcelona begonya.saez@uab.cat

Begonya Saez Tajafuerce. Begonya Saez Tajafuerce es profesora de filosofía en la Universitat Autònoma de Barcelona. Desde el año 2001 investiga acerca de la identidad en clave contemporánea y desde el año 2005 se desempeña como investigadora del grupo Cuerpo y Textualidad, con sede en la misma universidad. Centra su trabajo en las aproximaciones feministas al cuerpo en clave relacional desde un interés epistemológico, ético y político, y con especial remisión a los estudios de género, sexualidad y queer. Algunas de sus últimas publicaciones son: Representación fronteriza de la memoria histórica de las mujeres (2011), Debats: Un corpus para el cuerpo (2013) y, también, como editora, Cuerpo, memoria y representación: Adriana Cavarero y Judith Butler en diálogo (2014). 